\title{
First French Pilot Quality Assessment of the EndoPredict Test for Early Luminal Breast Carcinoma
}

\author{
JACQUELINE LEHMANN-CHE ${ }^{1,2}$, CATHERINE MIQUEL ${ }^{3,4}$, JENNIFER WONG ${ }^{1,2}$, \\ CELINE CALLENS ${ }^{5}$, ETIENNE ROULEAU ${ }^{6}$, VERONIQUE QUILLIEN ${ }^{7,8}$, NICOLAS LOZANO ${ }^{9}$, \\ ANNE CAYRE ${ }^{10}$, LUDOVIC LACROIX ${ }^{6}$, IVAN BIECHE ${ }^{5,11}$, PHILIPPE BERTHEAU ${ }^{3,4}$, LUIS TEIXEIRA ${ }^{2,12}$, \\ FREDERIQUE PENAULT LLORCA ${ }^{10,13}$, PIERRE JEAN LAMY ${ }^{9}$ and PATRICIA DE CREMOUX ${ }^{1,2}$, \\ FOR THE GFCO GROUP* \\ ${ }^{1}$ AP-HP, Molecular Oncology Unit, ${ }^{3}$ Pathology Department, \\ ${ }^{12}$ Breast Disease Unit Saint-Louis Hospital, Paris, France; \\ ${ }^{2}$ University Paris-Diderot, Sorbonne Paris Cité, INSERM/CNRS UMR944/7212, Paris, France; \\ ${ }^{4}$ University Paris-Diderot, Sorbonne Paris Cité, INSERM UMR-S-1165, Paris, France; \\ ${ }^{5}$ Pharmacogenomics Unit, Department of Genetics, Curie Institute, PSL University, Paris, France; \\ ${ }^{6}$ Medical Biology \& Pathology Department, Gustave Roussy, Villejuif, France; \\ ${ }^{7}$ Department of Biology, Centre de lutte contre le cancer Eugène Marquis, Rennes, France; \\ ${ }^{8}$ University Rennes 1, INSERM U1242, Rennes, France; \\ ${ }^{9}$ Institut d'Analyse Génomique Imagenome, Labosud, Montpellier, France; \\ ${ }^{10}$ Department of Surgical Pathology and Biopathology, Centre Jean-Perrin, Clermont-Ferrand, France; \\ ${ }^{11}$ University Paris-Descartes, Sorbonne Paris Cité, Paris, France; \\ ${ }^{13}$ University Clermont Auvergne, INSERM U1240, Clermont-Ferrand, France
}

\begin{abstract}
Background/Aim: Genomic signatures are needed for the determination of prognosis in patients with early stage, estrogen receptor (ER)-positive, human epidermal growth factor receptor 2 (HER2)-negative breast cancers. EndoPredict test is a RNA-based multigene assay that assesses the risk of 10-year relapse in this context. Quality assessment is a mandatory requirement for a laboratory to address the analytical quality of these molecular analyses. The aim of the study was to demonstrate the robustness of this prognostic test, its usefulness for the patient's treatment strategy, at the national level. Materials and Methods: This study presents a pilot quality assessment (QA) of the EndoPredict test using composite design, including the follow-up of internal control values ( $q R E F$ ) of the 12 genes of the assay for 151 independent tests and one formalin-fixed paraffin embedded (FFPE) breast
\end{abstract}

*GFCO: Groupe Français de Cytogénomique Oncologique.

Correspondence to: Dr. Patricia de Cremoux, MD, Ph.D., Molecular Oncology Unit, Saint-Louis Hospital, 1 avenue Claude Vellefaux, 75010 Paris, France. Tel: +33 142499388, e-mail: patricia.decremoux@aphp.fr

Key Words: Luminal breast cancer, prognosis molecular signature, EndoPredict test, Quality Assessment. cancer sample. The evaluation of the test was performed by comparing the results of six independent medical laboratories. Results: All measures were highly reproducible and quantification of the qREF showed a standard deviation of less than 0.50 and a coefficient of variation always of $<2 \%$. All laboratories found concordant results for the breast cancer samples. The mean EndoPredict (EP) score for the breast cancer sample was 4.97 \pm 0.24 . The mean of EPclin score was 3.07 \pm 0.05 . Conclusion: This first French independent reported $Q A$ assessed the robustness and reproducibility of the EndoPredict test. Such a simple composite design could represent an adapted QA for an expensive diagnostic test.

Breast carcinoma is the most frequent cancer diagnosed in women. Since the publication by Perou et al., it is known that breast cancers are heterogeneous and are represented by molecularly distinct subtypes, luminal, Human epidermal growth factor receptor 2 (HER2)-like and basal-like, each with different prognosis (1). Globally, luminal breast cancers had a better prognosis than basal-like, or triple negative breast cancers. However, despite a common hormonedependent presentation, luminal breast cancers presented clinical, histological and molecular heterogeneity. Furthermore, these subtypes, that represent more than $70 \%$ of early breast cancer, display varying degrees of sensitivity to chemotherapy (2). 
Recently, consensus conferences identified the necessity of molecular profiles in assessing the need for chemotherapy $(3,4)$. Genomic analyses based on selective gene expression within the luminal tumor subgroup (defined as estrogen receptor (ER)-positive and HER2-negative immunohistochemistry (IHC) profile) is now well established as complementary tool to determine the prognosis of patients with luminal tumors identified as having an intermediate prognosis by clinical and pathological parameters (3). The molecular profiles predict a calculated evaluation of the 10year-risk of distant relapse and help in deciding the adjuvant chemotherapy.

One of these tests, the EndoPredict test is a RNA-based multigene expression assay that assesses the risk of distant relapse in patients with early stage, ER-positive, HER2negative breast cancers, who will be treated by endocrine therapy. This assay combines the analysis of ER-signaling and proliferation- and differentiation-associated genes performed by reverse transcription (RT) and quantitative PCR on RNA extracted from formalin-fixed paraffin embedded (FFPE) samples to a 12-genes molecular EP score. This score includes the quantification of 8 cancerrelated genes, 3 house-keeping genes and one DNA reference gene. Each gene is assessed in triplicate in each patient sample. PCR manufacturer's internal positive and negative controlstested for each gene, are included in the kit and in each assay. The EPclin score, which is the final result, combines the molecular EP score with the pathological tumor size $(\mathrm{pT})$ and pathological nodal status $(\mathrm{pN})$ resulting in a molecular and clinicopathological score. Prognosis value of EP and EPclin scores, as predictor of early and late recurrence, was retrospectively validated in the Austrian Breast and Colorectal Cancer study group (ASBCG) 6 and 8 trials, and independently in the Spanish Breast Cancer Research Group (GEICAM) trial and in the Arimidex, Tamoxifen, Alone or in Combination (TransATAC) trial (5-7). Finally, samples were classified as low or high risk for distant relapse at 10 years according to the predefined cutoff value of 5 for the EndoPredict score (molecular risk score, EP). The threshold for EPclin to identify low or high risk was 3.3 corresponding to a risk of relapse of $10 \%$ at 10 years (integrated molecular and clinical risk score) $(5,8)$.

This study reports on the first pilot QA-initiated national of EndoPredict test using a composite design, including the follow-up of a minimum of 20 consecutive positive internal control values of the Endopredict test and a common sample from routine diagnostic analysis. This QA represents a mandatory requirement for a medical laboratory to ensure its competence in the frame of accreditation by the international organization for standardization (ISO) 15 189. This also allows all concerned platforms to realize the EndoPredict test and validate its accuracy.

\section{Materials and Methods}

Organization and participating Centres. In 2016, six French medical laboratories realized the EndoPredict test (Myriad, Salt Lake City, USA) in a routine diagnosis context (CJP, HSL, IC, GR, IM, and CEM). All laboratories initially participated to EndoPredict validation Training organized by Sividon Diagnostics/ Myriad Genetics (Cologne/Munchen, Germany) during the formation and set up of the test. All laboratories obtained the right to pre-specified results in reference to FFPE tumor and RNA samples that were mandatory to be allowed to use the test EndoPredict in a decentralized diagnosis context.

After one year, the Molecular Oncology Unit of Saint-Louis hospital organized, with the support of the "Groupe Français de Cytogénomique Oncologique" (GFCO), the first national pilot QA for EndoPredict test. The six French medical laboratories participated to the QA.

Preparation of $Q A$. Each laboratory performed the collection of the $\mathrm{Ct}$ values for the 12 genes of the qREF samples from at least 20 consecutive independent test runs from clinical routine and realized in the same period of the first semester of 2017. These results were included in the evaluation of the QA.

A breast tissue sample of interest was selected from the diagnosis routine analysis of the Molecular Oncology unit and the corresponding FFPE bloc was collected at the pathology Department of Saint-Louis Hospital. The choice of the sample was done by a biologist and a pathologist (PDC \& CM) and was based on i) sample tumor cell homogeneity among the block derived from breast lumpectomy, that will allow to generate enough slides for all participating laboratories and ii) was also selected with adequate infiltrative tumor cell content $(>30 \%)$. We selected a sample with $60 \%$ infiltrative tumor cells. In addition, the sample had an EP score near the threshold of 5 to ensure the robustness of EndoPredict test. One $10-\mu \mathrm{m}$ thick slide for analysis and one adjacent $4-\mu \mathrm{m}$ thick slide stained with HES were prepared for each laboratory. Tumor cellularity was controlled at the first and last slide by the pathologist.

Each medical laboratory received one HES slide and one nonstained slide, an anonymized pathological report indicating the tumor cell content, $\mathrm{pN}$ and $\mathrm{pT}$ of the sample, and the associate medical prescription for the test. Analysis in the routine workflow of the laboratories and reporting as in real life, including the raw data of the test and report, was mandatory for the participation to the QA process.

The QA was realized blinded in one round taking into account the cost of the test. Each laboratory communicated their results and raw data of the tested sample to Hospital Saint-Louis team.

Description of the EndoPredict test. Total RNA was extracted by each laboratory using silica bead-based, isolation method (VERSANT Tissue Preparation Reagents Kit; Siemens Healthcare Diagnostics, Tarrytown, NY, USA). The method includes deparaffinization, DNase I digestion and an RNA extraction step. DNA-free total RNA from one FFPE section was ultimately eluted with $100 \mu \mathrm{l}$ of elution buffer and stored at $-80^{\circ} \mathrm{C}$. The EP genes analysis was carried according to manufacturer's instruction by RT-qPCR. The EndoPredict test is based on the quantification of eight cancer-related transcripts genes from estrogen receptors, proliferation and apoptosis signaling pathways genes (BIRC5, 


\begin{tabular}{|l|l|c|c|c|c|c|c|c|c|c|c|c|c|}
\hline & & 1 & 2 & 3 & 4 & 5 & 6 & 7 & 8 & 9 & 10 & 11 & 12 \\
\hline & & AZGP1 & BIRC5 & OAZ1 & DHCR7 & IL6ST & MGP & CALM2 & RBBP8 & STC2 & UBE2C & RPL37A & HBB \\
\hline Sample & A & & & & & & & & & & & & \\
\hline & B & & & & & & & & & & & & \\
\hline & C & & & & & & & & & & & & \\
\hline qREF (10ng) & D & $\begin{array}{c}\text { HBB- } \\
\text { ADN }\end{array}$ & qREF & qREF & qREF & qREF & qREF & qREF & qREF & qREF & qREF & qREF & AZGP1 \\
\hline NTC & E & NTC & NTC & NTC & NTC & NTC & NTC & NTC & NTC & NTC & NTC & NTC & NTC \\
\hline & F & & & & & & & & & & & & \\
\hline & G & & & & & & & & & & &
\end{tabular}

Figure 1. Presentation of genes and the layout of the PCR plate for assessment of one tumor samples (UNO plate) of EndoPredict test. HBB: Hemoglobin subunit beta; BIRC5: baculoviral IAP repeat containing 5 (survivin); OAZ1: ornithine decarboxylase antizyme 1; DHCR7: 7dehydrocholesterol reductase; IL6ST: interleukin 6 signal transducer; MGP: matrix Gla protein; CALM2: calmodulin 2; RBBP8: retinoblastoma binding protein 8; STC2: stanniocalcin 2; UBE2C: ubiquitin-conjugating enzyme E2C; RPL37A: ribosomal protein L37a; AZGP1: alpha-2glycoprotein 1 zinc-binding; qREF: internal positive controls; NTC: no template control.

UBE2C, DHCR7, RBBP8, IL6ST, AZGP1, MGP and STC2) and three reference genes (CALM2, OAZ1 and RPL37A) and one DNA control gene (HBB). In each laboratory, the sample was analyzed in triplicate for each gene, in a 96-well UNO plate using either Versant (System VERSANT® ${ }^{\mathrm{k} P C R}$ module AD) or Agilent $(\mathrm{Mx} 3005 \mathrm{P}$ qPCR, Stratagene) device. Positive (qREF) and negative (NTC) internal controls provided by the manufacturer to validate each plate were also analyzed in the same run. All centers applied the same design of plates as shown in Figure 1. The thermal protocol included $30 \mathrm{~min}$ at $50^{\circ} \mathrm{C}, 20.5 \mathrm{~min}$ at $8^{\circ} \mathrm{C}$ and $2 \mathrm{~min}$ at $95^{\circ} \mathrm{C}$, followed by 40 cycles of $15 \mathrm{sec}$ at $95^{\circ} \mathrm{C}$ and $30 \mathrm{sec}$ at $60^{\circ} \mathrm{C}$.

The calculation of the molecular EP score was previously published by Filipitis et al. (5). The molecular EP score ranges from 0 to 15 . The higher values indicate a higher risk of recurrence. The EPclin score is a combination of EP score and two pathological parameters (pathological node involvement - $\mathrm{pN}$ and pathological tumor size - pT). Nonlinear values were used for the construction of the EPclin score: if $\leq 1 \mathrm{~cm}$; if $>1$ to $\leq 2 \mathrm{~cm}$; if $>2 \mathrm{~cm}$ to $\leq 5 \mathrm{~cm}$ and if $>5 \mathrm{~cm}$ and 1: negative node involvement; $2: 1$ to 3 positive nodes; 3 : 4 to 10 positive nodes and 4: $>10$ positive nodes. EP and EPclin scores were calculated as described previously (5) using a web-based implementation (https://www1.EndoPredict.com) to process analytical PCR results into EP and EPclin scores in addition to quality control. Finally, based on the EPclin score with cutoff value of 3.3, the web-based software classified the patient as low or high risk of distant metastasis.

Evaluation of the results. We evaluated the accuracy and reproducibility of the EndoPredict test, using the value of the CT for the 12 genes of the qREF samples from 151 consecutive independent tests.

The results of the sample analysis were compared with the initial diagnostic analysis, performed in the routine diagnosis of the Molecular Oncology Laboratory (Hôpital Saint-Louis). Quantitative and qualitative results were evaluated: the comparison includes the EP test results, the EPclin test results, and the predicted risk of relapse at 10 years.

The results were evaluated blinded by two biologists (PDC and JLC) and a report generated including results and efficiency of the QA. It was transmitted to each participating laboratory.
In this manuscript, the essential elements of "Reporting recommendations for tumor marker prognostic studies" (REMARK) were included (9).

\section{Results}

We have compared the $\mathrm{Ct}$ values of the twelve positive internal controls (qREF) included in each test for 151 different consecutive plates, analyzed in different laboratories. Results are presented in Table I. All results for each gene are highly reproducible. Quantification of expression of all control target genes showed a standard deviation of less than 0.50 and a coefficient of variation always $<2 \%$.

The results of the tumor sample are presented in Table II. All results were qualitatively and quantitatively concordant. All laboratories found that the risk of distant relapse was low, inferior to $10 \%$. The mean of the molecular EP score was 4.97 and the standard deviation was 0.24 . The mean EPclin score was 3.07 and the standard deviation was 0.05 and the mean of the risk of distant metastasis after 10 years was $8 \%$ with a standard deviation $<1 \%$.

\section{Discussion}

Many ER-positive breast cancer patients have an excellent prognosis and have little or no benefit from the addition of adjuvant chemotherapy. A major issue in the treatment strategy of breast luminal cancer is to identify patients who will benefit the most from adjuvant systemic chemotherapy. An alternative is to determine which patients will not benefit from adjuvant chemotherapy. Genomic somatic panel analysis has allowed better characterization of breast carcinoma clinical outcome (10). More recently, commercial genomic signatures for luminal early breast carcinoma have become increasingly important for prognostic evaluation. They are referenced for their use in Expert Consensus Conferences $(4,5,11,12)$. These analyses 
Table I. Evaluation of the mean, median and standard deviation of 151 consecutive analyses of EndoPredict internal positive controls.

\begin{tabular}{lcccccccccccc}
\hline Ct values of target genes & $H B B$ & \multirow{2}{*}{ BIRC5 } & OAZ1 & DHCR7 & IL6ST & MGP & CALM2 & RBBP8 & STC2 & UBE2C & RPL37A & AZGP1 \\
\hline Mean & 27.56 & 26.82 & 23.03 & 24.10 & 24.07 & 25.41 & 20.88 & 26.00 & 24.59 & 24.27 & 18.71 & 25.83 \\
SD* $_{\text {CV }}^{* *}$ & 0.39 & 0.40 & 0.46 & 0.30 & 0.27 & 0.29 & 0.25 & 0.27 & 0.30 & 0.38 & 0.22 & 0.28 \\
Median & $1.43 \%$ & $1.49 \%$ & $1.99 \%$ & $1.23 \%$ & $1.12 \%$ & $1.15 \%$ & $1.19 \%$ & $1.03 \%$ & $1.20 \%$ & $1.56 \%$ & $1.20 \%$ & $1.07 \%$ \\
MIN & 27.57 & 26.87 & 23.10 & 24.12 & 24.05 & 25.43 & 20.88 & 25.98 & 24.62 & 24.29 & 18.72 & 25.85 \\
MAX & 26.43 & 25.79 & 21.97 & 23.14 & 23.29 & 24.39 & 20.20 & 25.16 & 23.58 & 23.17 & 17.98 & 25.05 \\
& 28.77 & 27.73 & 23.93 & 24.99 & 24.82 & 26.17 & 21.69 & 26.88 & 25.32 & 25.27 & 19.50 & 26.67 \\
\hline
\end{tabular}

HBB: Hemoglobin subunit beta; BIRC5: Baculoviral IAP repeat containing 5 (survivin); OAZ1: ornithine decarboxylase antizyme 1; DHCR7: 7dehydrocholesterol reductase; IL6ST: interleukin 6 signal transducer; $M G P$ : matrix Gla protein; CALM2: calmodulin 2; RBBP8: RB binding protein 8 endonuclease; STC2: stanniocalcin 2; UBE2C: ubiquitin conjugating enzyme E2 C; RPL37A: ribosomal protein L37a; AZGP1: alpha-2-glycoprotein 1 zinc-binding. ${ }^{*}$ SD: Standard deviation; $* * C V$ : coefficient of variation.

were performed in medical laboratories, as a routine diagnosis context from RNA extracted from FFPE tissue (5, 13-15). Despite the poor quality of nucleic acid extracted in these conditions, many studies have demonstrated that FFPE tissues could be reliable material for molecular oncology testing, either from DNA but also from RNA. Consequently, quality assurance is essential for molecular diagnostic management of solid tumors to ensure patient safety. Good quality assurance included a minimum annual external quality control. This is included in the standard developed by the International Organisation for Standardization's Technical Committee ISO 15189 form for good laboratory practice. This is a major warrant of accuracy for decentralized tests that cannot be performed in foreign centralized tests with different local rules.

The EndoPredict test is a RNA-based multigene expression assay to predict the likelihood of distant recurrence in ERpositive/HER2-negative breast cancer patients treated with adjuvant endocrine therapy. Furthermore, the clinical interest for the test was recently confirmed by Sestak et al. The authors conducted the first large within-patient comparison of the multigene signatures, including Endopredict test, in the retrospective TransATAC ancillary study (16). The authors showed that the EndoPredict test provided independent prognostic information for women with early breast cancers with node-negative and 1 to 3 positive nodes in a series of 774 post-menopausal patients with luminal breast cancer (16). The test is designed to be used in a decentralized setting in molecular oncology laboratories $(5,17)$. These conditions of analysis allowed a good supervision of the implementation of the analysis and a rapid realization of the test, adapted to the early breast cancer for patients and clinicians.

EndoPredict test was also recently compared with a free web-based prognostication tool named NHS PREDICT, in a retrospective cohort of 120 patients with ER-positive/HER2negative breast cancer patients. The authors showed less accuracy of this web-tool to predict the need for chemotherapy (18).
Table II. Detailed result of EndoPredict scores and evaluated risk obtained in the 6 medical laboratories.

\begin{tabular}{lccc}
\hline Centre & EP & EpClin & Risk of relapse at 10 years \\
\hline 1 & 4.9 & 3.1 & $8 \%$ \\
2 & 5.2 & 3.1 & $9 \%$ \\
3 & 5.2 & 3.1 & $8 \%$ \\
4 & 5.1 & 3.1 & $8 \%$ \\
5 & 4.6 & 3 & $7 \%$ \\
6 & 4.8 & 3 & $8 \%$ \\
Mean $[\mathrm{SD}]$ & $4.97(0.24)$ & $3.07(0.05)$ & $8 \%(0.6 \%)$ \\
\hline
\end{tabular}

The initial qualification of each laboratory included both the complete training (3 days full) and the validation of external quality controls, including 8 different reference FFPE samples provided by the manufacturer. The samples were provided as blank slides, so the complete process was analyzed and validated in this first step of implementation. The complete success in analyzing the test samples was mandatory to be allowed to begin the analyses in a routine diagnosis context.

After a maximum of one-year use, a new essential independent quality control assessment was developed for the 6 French medical laboratories that performed the analysis at the date of the QA. This QA was organized with the support of the "Groupe Français de Cytogénomique Oncologique" (GFCO) and Gen\&Tiss, that drives the annual external quality assessment for lung, colon, melanoma or ovaries somatic molecular testing and that had a large practical experience for QA (19). Taking into account the cost of the EndoPredict test, one characterized sample was used for this first pilot QA. Furthermore, we added, in this pilot QA, the evaluation of the robustness and reproducibility of the positive internal controls (12 in each kit) of all target and reference genes included in each test, by adding, at least, the results of 20 consecutive analyses performed in 2017 by each laboratory. 
The performances of the test were good, with $100 \%$ concordance in the results of the test sample with regard to classification into low risk of distant metastasis. Moreover, the standard deviation of the EP and EPclin scores in the 6 laboratories was low, 0.24 and 0.05 , respectively. These results are similar to results of the decentralized analysis of the EndoPredict test that was previously performed with 7 pathology laboratories in Germany, Switzerland, and Austria with 10 reference tumor samples (8). They also found a concordance of risk classification of $100 \%$ and a similar standard deviation of 0.25 . Our study also showed highly concordant results for more than 150 analyses of the positive internal control target genes.

These results constitute the first French independent reported pilot QA for "Breast luminal molecular signatures" realized for EndoPredict test. This QA assessed the robustness and the reproducibility of the EndoPredict analysis. Given the emerging new biomarkers and technologies that represent challenges for clinical implementation, QA realization is crucial for improving quality assurance in molecular diagnostics whatever the test will be.

Such a simple composite design as reported here, including one sample and the analysis of a limited series of consecutive positive controls can represent an adapted QA for expensive diagnostic tests.

\section{Conflicts of Interest}

None of the Authors have any competing interests in regards to this study.

\section{Acknowledgements}

The Authors would like to thank C Brunin, B Geslot, B Filliol and C Wittmer for their helpful technical expertise. This research did not receive any specific grant from funding agencies in the public, commercial or not-for-profit sectors.

\section{References}

1 Sorlie T, Perou CM, Tibshirani R, Aas T, Geisler S, Johnsen H, Hastie T, Eisen, MB, van de Rijn M, Jeffrey SS, Thorsen T, Quist H, Matese JC, Brown PO, Botstein D, Lonning PE and Borresen-Dale AL: Gene expression patterns of breast carcinomas distinguish tumor subclasses with clinical implications. Proc Natl Acad Sci USA 98: 10869-10874, 2001.

2 Hart CD, Sanna G, Siclari O, Biganzoli L and Di Leo A: Defining optimal duration and predicting benefit from chemotherapy in patients with luminal-like subtypes. Breast Suppl 2: S136-142, 2015.

3 Harris LN, Ismaila N, McShane LM, Andre F, Collyar DE, Gonzalez-Angulo AM, Hammond EH, Kuderer NM, Liu MC, Mennel RG, Van Poznak C, Bast RC and Hayes DF; American Society of Clinical Oncology: Use of biomarkers to guide decisions on adjuvant systemic therapy for women with early- stage invasive breast cancer: American Society of Clinical Oncology Clinical Practice Guideline. J Clin Oncol 34: 11345110, 2016.

4 Senkus E, Kyriakides S, Ohno S, Penault-Llorca F, Poortmans P, Rutgers E, Zackrisson S and Cardoso F; ESMO Guidelines Committee. Primary breast cancer: ESMO Clinical Practice Guidelines for diagnosis, treatment and follow-up. Ann Oncol Suppl 5: v8-30, 2015.

5 Filipits M, Rudas M, Jakesz R, Dubsky P, Fitzal F, Singer CF, Dietze O, Greil R, Jelen A, Sevelda P, Freibauer C, Müller V, Jänicke F, Schmidt M, Kölbl H, Rody A, Kaufmann M, Schroth W, Brauch H, Schwab M, Fritz P, Weber KE, Feder IS, Hennig G, Kronenwett R, Gehrmann M and Gnant M: A new molecular predictor of distant recurrence in ER-positive, HER2-negative breast cancer adds independent information to conventional clinical risk factors. Clin Cancer Res 17: 6012-6020, 2011.

6 Martin M, Brase JC, Calvo L, Krappmann K, Ruiz-Borrego M, Fisch K, Ruiz A, Weber KE, Munarriz B, Petry C, Rodriguez CA, Kronenwett R, Crespo C, Alba E, Carrasco E, Casas M, Caballero R and Rodriguez-Lescure A: Clinical validation of the EndoPredict test in node-positive, chemotherapy-treated ER+/HER2- breast cancer patients: results from the GEICAM 9906 trial. Breast Cancer Res 16: R38, 2014.

7 R. Buus, I. Sestak, R. Kronenwett, C Denkert, P. Dubsky, K. Krappmann, M Scheer, C Petry, J Cuzick and M Dowsett: Comparison of EndoPredict and EPclin with Oncotype DX recurrence score for prediction of risk of distant recurrence after endocrine therapy. J Natl Cancer Inst 108: 1-7, 2016.

8 Denkert C, Kronenwett R, Schlake W, Bohmann K, Penzel R, Weber KE, Höfler H, Lehmann U, Schirmacher P, Specht K, Rudas M, Kreipe HH, Schraml P, Schlake G, Bago-Horvath Z, Tiecke F, Varga Z, Moch H, Schmidt M, Prinzler J, Kerjaschki D, Sinn BV, Müller BM, Filipits M, Petry C and Dietel M: Decentral gene expression analysis for ER+/Her2- breast cancer: results of a proficiency testing program for the EndoPredict assay. Virchows Arch 460: 251-259, 2012.

9 McShane LM, Altman DG, Sauerbrei W, Taube SE, Gion M and Clark GM: Statistics Subcommittee of NCI-EORTC Working Group on Cancer Diagnostics. Reporting recommendations for tumor MARKer prognostic studies (REMARK). Breast Cancer Res Treat 100: 229-235, 2006.

10 va't Veer LJ, Dai H, van de Vijver MJ, He YD, Hart AA, Bernards $\mathrm{R}$ and Friend $\mathrm{SH}$ : Expression profiling predicts outcome in breast cancer. Breast Cancer Res 5: 57-58, 2003.

11 Curigliano G, Burstein HJ, P Winer E, Gnant M, Dubsky P, Loibl S, Colleoni M, Regan MM, Piccart-Gebhart M, Senn HJ and Thürlimann B: St. Gallen International Expert Consensus on the Primary Therapy of Early Breast Cancer 2017, André F, Baselga J, Bergh J, Bonnefoi H, Y Brucker S, Cardoso F, Carey L, Ciruelos E, Cuzick J, Denkert C, Di Leo A, Ejlertsen B, Francis P, Galimberti V, Garber J, Gulluoglu B, Goodwin P, Harbeck N, Hayes DF, Huang CS, Huober J, Hussein K, Jassem J, Jiang Z, Karlsson P, Morrow M, Orecchia R, Osborne KC, Pagani O, Partridge AH, Pritchard K, Ro J, Rutgers EJT, Sedlmayer F, Semiglazov V, Shao Z, Smith I, Toi M, Tutt A, Viale G, Watanabe T, Whelan TJ and Xu B: De-escalating and escalating treatments for early-stage breast cancer: the St. Gallen International Expert Consensus Conference on the Primary Therapy of Early Breast Cancer 2017. Ann Oncol 28: 1700$1712,2017$. 
12 Duffy MJ, Harbeck N, Nap M, Molina R, Nicolini A, Senkus E and Cardoso F: Clinical use of biomarkers in breast cancer: Updated guidelines from the European Group on Tumor Markers (EGTM). Eur J Cancer 75: 284-298, 2017.

13 Sparano JA, Gray RJ, Makower DF, Pritchard KI, Albain KS, Hayes DF, Geyer CE Jr, Dees EC, Perez EA, Olson JA Jr, Zujewski J, Lively T, Badve SS, Saphner TJ, Wagner LI, Whelan TJ, Ellis MJ, Paik S, Wood WC, Ravdin P, Keane MM, Gomez Moreno HL, Reddy PS, Goggins TF, Mayer IA, Brufsky AM, Toppmeyer DL, Kaklamani VG, Atkins JN, Berenberg JL and Sledge GW: Prospective Validation of a 21-Gene Expression Assay in Breast Cancer. N Engl J Med 373: 2005-2014, 2015.

14 Cardoso F, van't Veer LJ, Bogaerts J, Slaets L, Viale G, Delaloge S, Pierga JY, Brain E, Causeret S, DeLorenzi M, Glas AM, Golfinopoulos V, Goulioti T, Knox S, Matos E, Meulemans B, Neijenhuis PA, Nitz U, Passalacqua R, Ravdin P, Rubio IT, Saghatchian M, Smilde TJ, Sotiriou C, Stork L, Straehle C, Thomas G, Thompson AM, van der Hoeven JM, Vuylsteke P, Bernards R, Tryfonidis K, Rutgers E and Piccart M: MINDACT Investigators. 70-Gene Signature as an Aid to Treatment Decisions in Early-Stage Breast Cancer. N Engl J Med 375: 717729, 2016.

15 Gnant M, Filipits M, Greil R, Stoeger H, Rudas M, BagoHorvath Z, Mlineritsch B, Kwasny W, Knauer M, Singer C, Jakesz R, Dubsky P, Fitzal F, Bartsch R, Steger G, Balic M, Ressler S, Cowens JW, Storhoff J, Ferree S, Schaper C, Liu S, Fesl C, and Nielsen TO: Austrian Breast and Colorectal Cancer Study Group. Predicting distant recurrence in receptor-positive breast cancer patients with limited clinic-pathological risk: using the PAM50 Risk of Recurrence score in 1478 postmenopausal patients of the ABCSG- 8 trial treated with adjuvant endocrine therapy alone. Ann Oncol 25: 339-345, 2014.

16 Sestak I, Buus R, Cuzick J, Dubsky P, Kronenwett R, Denkert C, Ferree S, Sgroi D, Schnabel C, Baehner FL, Mallon E and Dowsett M: Comparison of the performance of 6 prognostic signatures for estrogen receptor-positive breast cancer: A secondary analysis of a randomized clinical trial. JAMA Oncol, 2018. doi: 10.1001/jamaoncol.2017.5524. [Epub ahead of print].
17 Kronenwett R, Bohmann K, Prinzler J, Sinn BV, Haufe F, Roth C, Averdick M, Ropers T, Windbergs C, Brase JC, Weber KE, Fisch K, Mûller BM, Schmidt M, Filipits M, Dubsky P, Petry C, Dietel $M$ and Denkert C: Decentral gene expression analysis: analytical validation of the Endopredict genomic multianalyte breast cancer prognosis test. BMC Cancer 12: 456, 2012.

18 Mokbel K, Wazir U, El Hage Chehade H, Manson A, Choy C, Moye V and Mokbel K: A Comparison of the performance of EndoPredict clinical and NHS PREDICT in 120 patients treated for ER-positive breast cancer. Anticancer Res 37: 6863-6869, 2017.

19 Dequeker EM, Keppens C, Egele C, Delen S, A. Lamy, A. Lemoine, Dequeker EM, Keppens C, Egele C, Delen S, Lamy A, Lemoine A, Sabourin JC, Andrieu C, Ligtenberg M, Fetique D, Tops B, Descarpentries C, Blons H, Denoux Y, Aube C, Penault-Llorca F, Hofman P, Leroy K, Le Marechal C, Doucet L, Duranton-Tanneur V, Pedeutour F, Soubeyran I, Côté JF, Emile JF, Vignaud JM, Monhoven N, Haddad V, Laurent-Puig P, van Krieken H, Nowak F, Lonchamp E, Bellocq JP and Rouleau E: Three rounds of external quality assessment in France to evaluate the performance of 28 platforms for multiparametric molecular testing in metastatic colorectal and non-small cell lung cancer. J Mol Diagn 18: 205-214, 2016.
Received March 1, 2018

Revised April 5, 2018

Accepted April 10, 2018 